\title{
Het die tekslinguistiek enige implikasies vir die studie van literatuur?
}

\begin{abstract}
It is generally accepted that the study of linguistics and literary theory can benefit from each other. The question asked in this anticle is whether the principles and methods of the developing discipline of text linguistics will have any implications for the better understanding of literary texts. It is argued that the study of text linguistics - because of its interdisciplinary nature - certainly has the potential for this, but that knowledge of the principles and methods of this discipline should not be regarded as essential for the obtaining of any insights in literary texts.
\end{abstract}

\section{Inleiding 1}

Deur die loop van jare was daar altyd 'n noue band tussen aspekte van die letterkunde en aspekte van die linguistiek (vgl. Du Plessis, 1983:157). Die tekslinguistiek het in der waarheid in die sewentigerjare heelwat 'geleen' by die metodologie van literêre teorie (vgl. Garcia-Berrio, 1979:33). Wat egter in hierdie artikel aangeraak word, is die gedagte dat daar vandag nie meer soseer na die aard en metodes van die literêre teorie gekyk word om die linguistiek te baat nie, maar eerder die omgekeerde: daar is 'n gedagterigting wat meen dat kennis van die linguistiek (beginsels en metodes) wel kan bydra om meer van die literêre teks self te wete te kom - vergelyk in hierdie verband byvoorbeeld Widdowson (1975:1) se vroeë siening: "I believe that linguistics does have something to contribute to literary criticism, just as literary criticism has something to contribute to linguistics ..." Dié siening is op direkte of indirekte wyse ondersteun in talle ander publikasies oor die jare ${ }^{2}$ en word vandag selfs as 'n redelik voldonge feit aanvaar.

1 Hierdie artikel vorm deel van 'n omvattende navorsingsprojek oor die Afrikaanse tekslinguistiek. Finansiële bystand van die Raad vir Geesteswetenskaplike Navorsing, asook van die Universiteit van Kaapstad en die PU vir CHO word hiermee graag met dank erken. Die menings wat hicr uitgespreck word, is dié van die outcur en moet geensins aan die onderskeie instansies tocgeskryf word nie.

2 Vergelyk in hierdie verband o.m. Adriaens (1973); Bal (1981); Bertinetto (1979:146-153); Beukes (1989); Carter \& Burton (1982); Chapman (1973); Ching (1980); Coetzee (1982); Copeland (1984:20-24); Culler (1975); Fabb (1988); Falk (1978); Fowler (1977, 1981, 1986); Gräbe (1984); Gutwinski (1976); Hubbard (1981); Jacobson (I960); Jefferson \& Robey (1982); Leech (1969); Liebenberg (1983); Merrill (1985:1-5); Ohlhoff (1983(a), 1983(b), 1985); Ponelis 
2. Die bydrae van die linguistiek tot literatuurstudie: algemene voordele.

\subsection{Die bydrae van (teks-)linguistiese metodes?}

Die vraag wat hier beantwoord moet word, is: presies watter bydrae kan kennis van die (teks-)linguistiek se beginsels en metodes wel lewer tot beter begrip van literêre tekste? Ohlhoff (1983(a):169) sê as ons aanvaar dat "... taal 'n essensiële rol speel in die opbou van die betekenis in 'n literêre werk, dan is dit vanselfsprekend dat die insigte van die taalwetenskap die literatuuronderrig net ten goede kan kom" (my kursiverings W.A.M.C.). Du Plessis (1983:157) meen dat die "suiwer linguistiese analise" van byvoorbeeld 'n gedig "... die letterkundige kan help in sy uiteindelike interpretasie van die gedig" (my kursivering - W.A.M.C.).

\subsection{Die voordele van kennis van die linguistiek}

Botha (1983:1-2) sluit hierby aan deur - na aanleiding van opmerkings deur Traugott en Pratt (1980:9-20) - eksplisiet te sê dat kennis van die linguistiek aan studente van die literatuur algemene voordele bied. Kennis van die linguistiek bied onder andere

\footnotetext{
(a) 'n basis waarop ons beter kan begryp waarom ons ervaar wat ons wel crvaar by die lees van 'n literére teks;

(b) terminologie met behulp waarvan ons op 'n toereikende manier oor die taalstruktuur ("verbal structure") van 'n literêre teks kan praat;

(c) metodes met behulp waarvan ons kan aandui presies hoc ons ervaring van 'n literêre teks mede deur die taalstruktuur daarvan bepaal word;

(d) middele met behulp waarvan sekere interpretasieprobleme beredencerd opgelos kan word deur vir 'n teks aan te toon welkc taalstruktuur(e) daarvoor moontlik is en welke minder moontlik of onmoontlik is;

(e) 'n perspektief op die teks wat waarborg dat ons al die gepaste vrae oor die taal daarvan stel sodat ons 'n konsekwente analise daarvan kan gee;

(f) 'n omvattende begripsraamwerk waarbinne ons die rec̈lmatighede in die taal van die teks kan herken en sistematies kan beskryf.
}

\subsection{Die winste van 'n (teks-)linguistiese benadering}

Die aspekte wat Botha (1983:1-2) hier genoem het, hou volgens Ohlhoff (1983(a):175-176) weer die volgende belangrike winste in:

* Dit kan 'n bydrae lewer tot presieser, verantwoorder kommunikasie wanneer daar oor die taal van 'n kunswerk gepraat word. Vergelyk ook hier Hubbard (1981:112) se op-

(1975); Renkema (1987: 287); Robey (1982); Schogt (1988:82-95); Senekal (1986); Toolan (1988); Traugott \& Pratt (1980); Van Coller \& Van Jaarsveld (1984); Van Dijk (1972:165 e.v.; Van Dijk (1985); Van Luxemburg et al. (1983, 1987); Van Rensburg (1967); Wybenga (1983, 1988). Steenberg (1986:18-30) bied 'n goeie oorsig oor wat al in die verband in Afrikaans gedoen is. 
merking: "Linguists can assist here by providing a basic terminology which can only improve the two-way communication between teacher and student whenever the language of a work is under discussion ..."

* Dit kan help om 'n 'beskrywende houding' mee te bring deur die bewusmaking (a) dat taal op 'n bepaalde wyse in 'n besondere konteks gebruik word en (b) dat 'n verantwoorde teoretiese raamwerk sal kan bydra om te verklaar waarom die taal gebruik is soos dit wel gebruik is.

* Dit kan bydra dat die leser (van die literêre teks) (a) sy intuïtiewe aanvoelings stewiger fundeer, (b) sy sienings genuanseerder stel en (c) ook literêr-kritiese (en -teoretiese) probleme noukeuriger fundeer. Hubbard (1981:111) sê, gegewe die gedagte dat die linguis die beskrywende raamwerk moet verskaf vir die analise van taal en die wyse waarop dit gebruik word, behoort hy ook in staat te wees om hiermee 'n soort "... objective sheet-anchor" te verskaf, dit wil sê "... a means of ensuring a sound basis for various sorts of critical judgement and interpretative comment".

* Dit kan bydra tot 'n beter begrip vir die wyse waarop literêre effekte geskep word deurdat die struktuurpatrone van die verskillende genres/tekstipes ondersoek kan word. Sodoende kan moontlike literêre probleme verhelder word - probleme soos: Waar lê die grense van 'n (besondere) literêre teks? Watter soort eenheid/samehang behoort 'n (besondere soort) teks te vertoon? Tot watter mate is 'n sin in 'n (besondere) teks verstaanbaar buite sy konteks? en so meer. (Vgl. Coetzee, 1982:49-50.)

* Dit kan 'n verklaring help bied nie net vir die semantiese interpretasie van lesers nie, maar ook vir die effektiewe impak óp en reaksie ván die leser - sodoende kan dit 'n bydrae binne die eksperimentele resepsie-ondersoek lewer.

- Dit kan die leser in staat stel (a) om die taal van die teks sistematies te ondersoek, (b) om bewustelik verskillende betekenisverhoudings na te gaan, (c) om die keuses van skrywers op 'n gefundeerde wyse te beskryf en te beoordeel. Uiteindelik vergemaklik en verhelder dit die nagaan van verbande tussen elemente in 'n teks.

Ohlhoff (1983(a):174) sê dat kennis van byvoorbeeld die verskillende soorte (leksikale) betekenisverhoudings soos sinonimie, antonimie en hiponimie nuttig aangewend kan word:

Die leser van literêre tekste wat bewus is van hierdie verhoudinge en begrippe is nie net in staat om makliker en presieser daaroor te kommunikeer nie, maar kan ook meer stelselmatig vrac oor betekenisverhoudings binne die teks vra, asook oor verhoudinge tussen teksbetekenisse en betekenisse buite die teks. Deur laasgenoemde kan hy dan bewustelik ondersock instel na die (patroon van) keuses wat die skrywer gemaak het vir bepaalde betekenisse en teen ander. Afleidings oor literêre implikasies kan ook so met groter vertroue gemaak word. ${ }^{3}$

3 Vergelyk ter illustrasie van hierdie punt Ohlhoff (1983(a):174-175) se voorbeeldontleding van 'n gedig deur Lina Spies. 


\section{Besondere voordele van die tekslinguistiek}

\subsection{Die linguistiese ondersoek van tekstualiteit}

Dit is die primêre doel van die tekslinguistiek om die tekstualiteit van tekste te ondersoek met behulp van alle linguistiese middele waaroor die ondersoeker beskik. ${ }^{4}$ Ten einde dit te kan doen, word sekere 'standaarde van tekstualiteit' onderskei wat by die beoordeling oor die aanvaarbaarheid al dan nie van 'n gegewe stuk taalgebruik as 'n teks in ag geneem word - dié standaarde 5 is die volgende: (a) kohesie 6 (met as besondere fokuspunte die patrone van verwysing, substitusie, ellips, leksikale kohesie en konjunksie in ondersoekte data), (b) koherensie, (c) intensionaliteit, (d) aanvaarbaarheid, (e) informatiwiteit, $(f)$ kontekstualiteit en $(\mathrm{g})$ intertekstualiteit.

\subsection{Die afsonderlike bydrae van die 'standaarde van tekstualiteit'}

Afgesien daarvan dat hierdie 'standaarde' gesamentlik die interpretasie van 'n teks kan beïnvloed, het elke standaard ook 'n afsonderlike bydrae te lewer:

* Kohesie: 'n ondersoek na die bindingspatrone in 'n teks met behulp van sintaktiese, semantiese, morfologiese en fonologiese metodes. So kan byvoorbeeld die verwysingstruktuur in 'n teks bepaal word: daar is verbande tussen onder meer naamwoorde (naamwoord : naamwoord, naamwoord : voornaamwoord); naamwoorde en bywoorde, en so meer; ook samehangende klankpatrone; leksikaal-semantiese skakeling, ensovoorts.

* Koherensie: 'n ondersoek na dit wat bydra dat 'n teks vir taalgebruikers sin maak en samehang vertoon. Is daar byvoorbeeld konseptuele skakeling tussen dit wat die taalgebruiker weet en dit wat hy uit die teks kan aflei?

* Intensionaliteit en aanvaarbaarheid: ondersoeke na die bydraes wat die deelnemers aan 'n teksgebeurtenis moet lewer om die teks as ' $n$ taalhandeling te laat slaag. Die pragmatiese benadering wat hier gevolg word, kan volgens Ohlhoff (1983(a):176) lig werp op

... dic probleem van die tydruimtelike oriëntering ${ }^{7}$ van skrywer en leser en op dic kwessic van hulle gedeelde kennis, dit kan help om gesprekke in literêre werke sistematies te benader en

4 Vergelyk in hicrdic verband o.m. Carstens (1992); De Beaugrande (1980:15, 1984:339, 1985:48); Fowlcr (1986:53-68).

5 De Bcaugrande en Dressler (1981) is die standaardwerk in hicrdie verband. Vergelyk o.m. ook Carstens (1987); De Beaugrande (1980:16-21, 1984:37-40, 1985:48-49); Fowler (1986:60-68); Hubbard (1989:89-112).

6 Dic standaardwerk oor kohesic is Halliday en Hasan (1976).

7 In Afrikaans is in onder meer Ohlhoff (1985); Senckal (1986); Snyman (1983(a), 1983(b)); Van Coller \& Van Jaarsveld (1984); Van Jaarsveld (1982 \& 1987) aspektc van dić problematick bespreek. 
dit kan 'n belangrike bydrae lewer om te bepaal wat 'n spreker in ' $n$ werk presies in en deur die taal wil doen, wat hy dus werklik wil sê.

- Informatiwiteit: 'n ondersoek na die wyse waarop taalelemente gebruik word om inligting in tekste aan te bied. Dit kan 'n aanduiding gee van die groter kommunikatiewe belang wat aan sekere taalelemente geheg word.

* Kontekstualiteit: 'n ondersoek na die invloed wat die (sosiale) kontekste waarin tekste voorkom, op die interpretasie van die teks het. Kennis van die sosiolinguistiek is hier 'n bate. Ohlhoff (1983(a):176) sê 'n kennis van die insigte van die sosiolinguistiek

... stel die leser onder meer in staat om op sock te wees na bepaalde verskynsels in die taalgebruik van figure in literêre werke en om sistematiese beskrywings en verklarings vir byvoorbeeld gemerkte en ongemerkte gebruik van taalitems te verskaf.

- Intertekstualiteit: 'n ondersoek na die faktore wat dit moontlik maak dat kennis van een teksstruktuur die interpretasie van ander soortgelyke teksstrukture sal beïnvloed.

Kennis van bogenoemde aspekte kan meehelp om beter insig te verkry in die gebruik van taal, onder meer in die gebruik van literêre taal. In hierdie opsig kan perspektiewe verkry deur 'n studie van die tekslinguistiek wel van waarde wees vir letterkundige analises.

\section{Wees realisties oor die bydrae van die tekslinguistiek}

Wybenga (1983:110-111) wys daarop dat 'n mens in gedagte moet hou dat 'n letterkundige/literator en 'n linguis verskillende doelstellings met 'n literêre teks sal hê. Albei kyk na die teks as kommunikasie-instrument, ${ }^{8}$ maar hulle benader dié instrument verskillend: die linguis wil vasstel hoe die vorm (en struktuur) van die teks met behulp van taal gemanifesteer/geskep word, dit wil sê hy het primêr ten doel om die taalkundige struktuur van 'n teks/stuk taal(gebruik) te bestudeer. Die letterkundige daarenteen betrek ook die struktuur by sy studie van 'n teks, maar hy stel 'n bykomende vraag, naamlik: Wat is die funksie van hierdie struktuur en hoe hou dit met die tema verband?

Vir die linguis is die literêre teks nie die enigste tekstipe wat hy kan ondersoek nie, maar dit is net nog 'n funksie waarin taal gebruik kan word - daarom is dit ook deel van die studieveld van die linguis. (Vgl. ook Steenberg, 1986:19, Traugott \& Pratt, 1980:20-21.) Sy linguistiese ondersoek van 'n literêre teks sal ook daarom nie hoofsaaklik gerig wees op die funksie van die literêre taal om die aandag op die tema as sodanig te vestig nie, maar eerder op hoe die taal ingespan word (struktuur, keuse van taalelemente, ens.) om die betrokke tema tot stand te bring. Die linguis se benadering tot die ontleding van teksvorme kan egter wel die literator steun in sy eie ontleding van tekste - dis dan in hierdie opsig dat die beginsels en metodes van die tekslinguistiek tóg 'n bydrae tot teksbegrip en teksinterpretasie kán lewer.

8 Botha (1983: 3) sê die 'brug' tussen taalwetenskap en literêrc studie lê juis in 'n gemecnskaplike doelstelling, namlik om kommunikatief-gebruikte taaluitings te ondersoek. Die taalwetenskap/linguistick bestudeer naamlik die beginsels in terme waarvan woorde en sinne gevorm en kommunikatief gebruik word, terwyl literatuurstudie uit die lees, analiseer en kritisecr van literatuur soos gemanifesteer in (kommunikatief bedoelde) tekste bestaan. Vergelyk Botha (1983:3) vir meer besonderhede in hierdie verband. 
Die argumente wat in 2.2 en 2.3 aangevoer is, behoort daarom nie gebruik te word as motivering vir 'n gedagte dat kennis van die tekslinguistiek essensieel is vir die studie van literatuur nie. Traugott en Pratt (1980:20) sê heel tereg in hierdie verband:

\begin{abstract}
... linguistics is not essential to the study of literature. Certainly onc does not need to know linguistics in order to read and understand literary works; and critical analysis has long been carried out without formal linguistic apparatus. However, linguistics can contribute a great deal to our understanding of $a$ text ... In this sense, although linguistics does not encompass liter ary criticism, it is relevant to all criticism". (My kursiverings - W.A.M.C.)
\end{abstract}

\title{
5. Samevatting
}

Die doel met enige wetenskaplike ondersoek is om meer te wete te kom oor 'n besondere onderwerp. Indien in 'n studie oor die tekslinguistiek aangeneem word dat die resultate van die ondersoek sal bydra tot nuwe insigte ten opsigte van ander dissiplines, is dit nie 'n siening wat ligtelik geïgnoreer kan word nie. In hierdie artikel is daar ook uitgewys dat die linguis 'n verantwoordelikheid het om steeds met behulp van sy metodes en beginsels weë te ondersoek om (ook literêre) tekste beter te begryp en te verklaar - Robins (1990:421) vat dié punt soos volg saam:

... it is part of the linguist's task and competence, by the application of the specific methods of linguistics, to analyse the forms and patterns of languages, and so to make explicit some of the features in them that in varying degrees, according to the nature of the work, constitute the material which the author must use and exploit in expressing himself to his public.

Ook (bl. 422-423):

... the linguist in applying his own methods to a specific body of linguistic material may be able to deepen the appreciation of different literary styles, and of the artistic uses of language, both his own and that of other people.

Daar moet egter duidelik daarteen gewaak word om die linguistiek - en in die besonder die tekslinguistiek - te sien as essensieel vir die begrip en interpretasie van literêre tekste. Die besondere metodes en beginsels van die tekslinguistiek het wel die potensiaal om 'n groot bydrae te lewer, maar dit moet beslis nie geïnterpreteer word as dié metode van teksondersoek om netelige literêre kwessies te verklaar nie.

\section{Bibliografie}

Adriaens, M. 1973. Literanumwetenskap en linguistiek. Leuven : Acco.

Bal, M. (red.) 1981. Literaire genres en hun gebruik. Over teksttypes en taalhoudingen. Muiderberg : Dick Coutinho.

Bertinetto, P.M. 1979. Can We Give an Unique Definition of the Concept 'Text'? Reflexions on the Status of Textlinguistics. In: Petöfi, J.S. (ed.) Questions of Tex Linguistics. Part I. Hamburg : Helmut Buske Verlag. p. 143-159.

Bcukes, M.P. 1989. Vooropstelling kohesie en koherensie in die poësie van T.T. Cloete. Ongepubliseerde verhandeling (M.A. - PUCHO).

Botha, R.P. 1983. Wat kan Taalwetenskap die student van literatuur bied? In: Sinclair, M. (red.) Taalwetenskap en die studie van literatuur. Spil Plus 8. Stellenbosch : Departement Algemene Taalwetcnskap. 
Carstens, W.A.M. 1987. De Beaugrande en Dressler (1981) se 'standaarde van tekstualitcit"'. $S A$. Tydsknf vir Taalkunde, 5(2):17-32.

Carstens, W.A.M. 1992. Dic studicterrein van dic tekslinguistick. (Referaat gelewer by LVSA-Kongrcs, Julie 1991, UNISA.)

Carter, R. \& Burton, D. (reds.) 1982. Literary Text and Language Study. London : Arnold.

Chapman, R. 1973. Linguistics and Literature. London : Edward Arnold.

Ching, M.K.L; Haly, M.C. \& R.F. Lunsford (eds.) 1980. Linguistic Perspective on Literature London : Routledge \& Kegan Paul.

Coetzee, J.M. 1982. Linguistics and Literaturc. In: Ryan, R. \& Van Zyl, S. (eds.) An Introduction to Contemporary Literary Theory. Johannesburg: Ad Donker. p. 41-52.

Copeland, J.E. (ed.) 1984. New Directions in Linguistics and Semiotics. Houston : Rice University.

Culler, J. 1975. Structuralist Poetics. Ithaca : Cornell University Press.

De Bcaugrande, R.A. 1980. Text, Discourse, and Process: Toward a Multidisciplinary Science of Texts. Norwood, N.J. : Ablex.

De Beaugrande, R.A. 1984. Text Production: Toward a Science of Composition. Norwood, N.J. : Ablex.

De Beaugrande, R.A. 1985. Text Linguistics in Discourse Studies. In: Van Dijk, T.A. (cd.) Handbook of Discourse Analysis. Vol. I: Disciplines of Discourse. London : Academic Press. p. 41-70.

De Beaugrande, R.A. \& Dressler, W.U. 1981. Introduction to Text Linguistics. London : Longman.

Du Plessis, H.G.W. 1983. Die verband tussen taal- en letterkunde. In: Sinclair, A.J.L. (red.) G.S. Nienaber - ' $n$ Huldeblyk. Bellville : UWK-Drukkers. p.157-166.

Fabb, N. c.a. (cds.) 1988. The Linguistics of Writing: Anguments between Language and Literature. New York: Methuen.

Falk, J.S. 1978. Linguistics and Language: A Survey of Basic Concepts and Implications. New York : John Wilcy and Sons.

Fowler, R. 1977. Linguistics and the Novel. London : Methuen.

Fowler, R, 1981. Literature as Social Discourse: the Practice of Linguistic Criticism. London : Batsford.

Fowler, R. 1986. Linguistic Criticism. Oxford : Oxford University Press.

Garcia-Bcrrio, A. 1979. Text and Sentencc. In: Petöfi, J.S. (ed.) Text vs. Sentence: Basic Questions of Terr Linguistics - Pant I. Hamburg: Helmut Buskc Verlag. p. 24-42.

Gräbe, I. (red.) 1984. Sintaksis in die poësie. Port Elizabeth : Universiteit van Porl Elizabeth. Navorsingspublikasie C 21.

Gutwinski, W. 1976. Cohesion in Literary Texts. Den Haag : Mouton.

Halliday, M.A.K \& Hasan, R. 1976. Cohesion in English. London : Longman.

Hubbard, E.H. 1981. The Role of Linguistics in the Study of Literary Texts. In: Maxwell-Mahon, W.D. (ed.) Critical Theory and Literany Texts. Pretoria : UNISA. p. 110-125.

Hubbard, E.H. 1989. Reference Cohesion, Conjunctive Cohesion and Relational Coherence in Student Academic Writing. Unpublished thesis. (D.Litt. et Phil. - UNISA.)

Jacobson, R. 1960. Closing Statements: Linguistics and Poetics. In: Sebeok, T. (ed.) Style in Language. Cambridge, Mass. : The MIT Press. p. 350-377.

Jefferson, A. \& Robcy, D. (cds.) 1982. Modern Literary Theory. A Comparative Introduction. London : Batsford Academic.

Lecch, G.N. 1969. A Linguistic Guide to English Poetry. London : Longman.

Liebenberg, W. 1983. Die rol van dic Taalwetenskap in die ontwikkeling van dic literatuurwetenskap. In: Sinclair, M. (red.) Taalwetenskap en die studie van literatuur. Spil Plus 8. Stcllenbosch : Departement Algemene Taalwetenschap. p. 31-43.

Merrill, F. 1985. A Semiotic Theory of Texts. Berlin/New York: Mouton de Gruyter.

Ohlhoff, C.H.F. 1983(a). 'n Brug tussen Taalwetenskap en Letterkunde: die bydrac van dic Taalwetenskap tot literatuuronderrig. In: Eksteen, L.C. \& Pretorius, R. (reds.) Objek en metode. Pretoria : Van Schaik. p. 169-177.

Ohlhoff, C. H.F. 1983(b). Teks, teks en ... teks. In: Sinclair, A.J.L. (red.) G.S. Nienaber - 'n Huldeblyk. Bellville : UWK-Drukkers. p. 389-396.

Ohlhoff, C.H.F. 1985. Taalkundige insigte en literêre tekste. Ongepubliseerde proefskrif. (D. Litt. - UP.)

Pone "s, F.A. 1975. Gedagtes oor teksontleding. In: Grové, A. P. (red.) In en om die letterkunde. Kaaps ad : HAUM. p. 91-99.

Rcnkema, J. 1937. Tekst en uitleg - Een inleiding in de tekswetenschap. Dordrecht : Foris. 
Robey, D. 1982. Modern Linguistics and the Language of Literature. In: Jefferson, A. \& Robey, D. (cds.) Modern Literary theory. A Comparative Introduction. London : Batsford Academic. p. $38-64$.

Robins, R.H. 1990. (4th revised edition) General Linguistics: An Introductory Survey. London/New York : Longman.

Schogt, H. 1988. Linguistics, Literary Analysis and Literay Translation. Toronto : University of Toronto Press.

Senckal, J. (red.) 1986. Teks, leser, konteks (Gedigte ontleed volgens eietydse metodes). Johannesburg : Perskor.

Snyman, H.J. 1983(a). Mirakel en muse. Kaapstad/Johannesburg : Perskor.

Snyman, H.J. 1983(b). Implikasic as taalverskynsel. In: Sinclair, M. (red.) Taalwetenskap en die studie van literatuur. Spil Plus. Stellenbosch : Departement Algemene Taalwetenskap. p. 44-51.

Stecnberg, A. M.M. 1986. Die funksie van leksikale herhaling in die kortprosabundel Een-entwintig van J.S. Rabie. Ongepublisecrde verhandeling. (M.A. - PU vir CHO (Vaaldriehockse Kampus).)

Toolan, M.J. 1988. Narrative: A Critical Linguistic Introduction. London/New York : Routledge.

Traugott, E.C. \& Pratt, M.L. 1980. Linguistics for Students of Literature. New York : Harcourt, Brace Jovanovich.

Van Coller, H.P. \& Van Jaarsveld, G.J. (reds.) 1984. Woorde as dade: Taalhandelinge en die letterkunde. Pretoria: Buttcrworth.

Van Dijk, T.A. 1972. Some Aspects of Text Grammar. A Study in Theoretical Linguistics and Poetics. Den Haag : Mouton.

Van Dijk T.A. (cd.) 1985. Discourse and Literature. Amsterdam/ Philadelphia : John Benjamins.

Van Jaarsveld, G.J. (red.) 1982. Wat sê jy? - Studies oor taalhandelinge in Afrikaans. Johannesburg : McGraw-Hill.

Van Jaarsveld, G.J. (red.) 1987. Wat bedoel jy? Pretoria : Serva.

Van Luxemburg, J.; Bal, M. \& Weststeijn, W.G. 1983. Inleiding in de Literatuurwetenschap. Muiderberg : Coutinho.

Van Luxemburg, J.; Bal, M. \& Weststeijn, W.G. 1987. Over Literantur. Muiderberg : Coutinho.

Van Rensburg, F.I.J. 1\%67. Taalkundige raakpunte van die literatuurstudic. Taalfasette, 3: 34-52.

Widdowson, H.G. 1975. Stylistics and the Teaching of Literatture. London : Longman.

Wybenga, D.M. 1983. Grammatiese tydsvergestalting in Afrikaans - 'n linguistiese ondersoek aan die hand van enkele Afrikaanse kortverhale. Ongepubliseerde proefskrif. (D. Litt. - PU vir CHO.)

Wybenga, D.M. 1988. Diskoersanalise en Stilistiek: 'n Inlciding. Pretoria : Serva.

\section{Potchefstroomse Universiteit vir CHO}


